\title{
Variational assimilation of Lagrangian trajectories in the Mediterranean ocean Forecasting System
}

\author{
J. A. U. Nilsson ${ }^{1, *}$, S. Dobricic ${ }^{2}$, N. Pinardi ${ }^{3}$, P.-M. Poulain ${ }^{4}$, and D. Pettenuzzo ${ }^{1}$ \\ ${ }^{1}$ National Institute of Geophysics and Vulcanology (INGV), Via Donato Creti 12, 40128 Bologna, Italy \\ ${ }^{2}$ Centro EuroMediterraneo per i Cambiamenti Climatici (CMCC), Bologna, Italy \\ ${ }^{3}$ Corso di Scienze Ambientali, Bologna University, Ravenna, Italy \\ ${ }^{4}$ The National Institute of Oceanography and Applied Geophysics (OGS), Trieste, Italy \\ *now at: Climate Modeling and Impacts Lab (UTMEA-ENEA), Rome, Italy
}

Correspondence to: J. A. U. Nilsson (j.a.u.nilsson@gmail.com)

Received: 21 November 2011 - Published in Ocean Sci. Discuss.: 20 December 2011

Revised: 12 March 2012 - Accepted: 13 March 2012 - Published: 30 March 2012

\begin{abstract}
A novel method for three-dimensional variational assimilation of Lagrangian data with a primitive-equation ocean model is proposed. The assimilation scheme was implemented in the Mediterranean ocean Forecasting System and evaluated for a 4-month period. Four experiments were designed to assess the impact of trajectory assimilation on the model output, i.e. the sea-surface height, velocity, temperature and salinity fields. It was found from the drifter and Argo trajectory assimilation experiment that the forecast skill of surface-drifter trajectories improved by $15 \%$, that of intermediate-depth float trajectories by $20 \%$, and moreover, that the forecasted sea-surface height fields improved locally by $5 \%$ compared to satellite data, while the quality of the temperature and salinity fields remained at previous levels. In conclusion, the addition of Lagrangian trajectory assimilation proved to reduce the uncertainties in the model fields, thus yielding a higher accuracy of the ocean forecasts.
\end{abstract}

\section{Introduction}

A novel method to correct ocean surface-velocity field predictions has been developed by implementing variational data assimilation of two-dimensional Lagrangian drifter trajectories in the Mediterranean ocean Forecasting System (MFS). Assimilation of drifter observations in ocean models has previously been attempted using various numerical methods, e.g. optimal interpolation (Molcard et al., 2003), nudging (Fan et al., 2004), and Kalman filtering (Ozgokmen et al., 2003), all with promising results.
The MFS provides operational forecasts and analyses for the Mediterranean Sea since 1998 (Pinardi et al., 2003), and the output is useful for multi-purpose near-real-time applications, such as search-and-rescue operations and oil-spill predictions (Coppini et al., 2011). In order to guarantee stateof-art ocean analyses, a three-dimensional data assimilation scheme denoted OceanVar (Dobricic and Pinardi, 2008) is under continuous development, and recently glider observations (Dobricic et al., 2010) and Argo-float trajectories (Nilsson et al., 2011) have been successfully assimilated.

The scope of the present study is to show some encouraging first results due to the implementation of the new driftertrajectory assimilation scheme. Moreover, additional numerical experiments were undertaken where drifter data were assimilated together with Argo-float trajectories at intermediate depth. It will be shown that the three-dimensional dataassimilation scheme (OceanVar) in MFS is capable of simultaneously correcting the surface and sub-surface velocity fields through Lagrangian trajectory increments. In addition, the modified MFS is able to maintain previous quality levels of the daily-mean sea surface height (SSH), temperature, and salinity model fields.

The study is structured as follows: Sect. 2 provides a brief overview of the MFS and the OceanVar assimilation scheme. The observational data sets and the numerical experiments are detailed in Sect. 3, the results are subsequently presented and discussed in Sect. 4, and finally Sect. 5 comprises some conclusions and an outlook. 


\section{The Mediterranean ocean Forecasting System}

\subsection{The ocean general circulation model}

The Mediterranean Forecasting System is a daily 10-day forecast system in operational use since 1998 (Pinardi et al., 2003; Pinardi and Coppini, 2010), and its ocean general circulation model (OGCM) is based on the Océan Parallélise code (Madec et al., 1998), which has subsequently been set up for the Mediterranean Sea by Tonani et al. (2008). The primitive equations were subjected to the Boussinesq and hydrostatic approximations, and discretized on a spherical grid with a horizontal resolution of $1 / 16^{\circ} \times 1 / 16^{\circ}$ and 71 un-evenly spaced vertical levels with a $3-\mathrm{m}$ resolution near the surface. In the present study, the model was set to produce daily 24-hour forecasts, and the output was saved as daily-averaged temperature, salinity, sea-level and horizontal velocity fields.

The MFS configuration does not include tides, thus modeled high frequency signals would be expected to be largely due to wind-induced inertial currents. The period of inertial currents $(2 \pi / f, f$ being the Coriolis parameter) depends on latitude and ranges between $17 \mathrm{~h}$ in the northern parts of the Mediterranean (Picco et al., 2010) to approximately $24 \mathrm{~h}$ in the south $\left(\sim 23 \mathrm{~h}\right.$ at $\left.32^{\circ} \mathrm{N}\right)$. Hence, the inertial period in the Levantine basin coincides more or less with the 24-hour averaging period of the MFS forecasts, and an assumption was made that the influence of inertial residuals in the daily model fields in this area would be minor.

The OceanVar operational assimilation cycle involves a wide range of observational data, from satellite-observed sea level anomalies (SLAs, Le Traon et al., 2003) and sea-surface temperatures (SSTs, Marullo et al., 2007), to temperature and salinity profiles from expendable bathytermographs (XBTs, Manzella et al., 2007) and Argo-float profilers (Poulain et al., 2007). The heat flux, on the other hand, is corrected by relaxing the modeled surface-layer temperatures towards the satellite-observed SST data (Dobricic et al., 2005).

\subsection{The Ocean Var assimilation scheme}

The model fields produced by the OGCM are corrected daily by the OceanVar data assimilation scheme described by Dobricic and Pinardi (2008), and a brief presentation of its main components is given in the Appendix. The assimilation procedure involves the minimization of a cost function that finds a maximum likelihood model state estimate based on the OGCM forecast of the background model state as well as all available observations. The corrected state vector contains the temperature, salinity, velocity and sea-level.

The non-linear cost function is linearized around the background state (Eq. A1), minimized by iterations, and the resulting model analyses are used to re-initialize the OGCM. The misfits, viz. the differences between the background fields and the observations, are saved daily, as they are use- ful for evaluating the quality of the model forecasts. The assimilation of surface-drifter positions requires the implementation of a non-linear trajectory model (Eq. A2) in the observational operator that maps the model to the observational space, hence facilitating comparisons between the Lagrangian observations and the modeled Eulerian fields. The non-linear particle advection equation was discretized and used for this purpose since its application has proved successful for assimilating Argo-float positions in the Mediterranean Sea; detailed descriptions of the trajectory model implementation and evaluations of the numerical experiments are available in Taillandier et al. (2006a,b); Nilsson et al. (2011).

Thus, the trajectory model was modified to also assimilate surface-drifter trajectories, and drifter-position forecasts were calculated "on-line" by daily 24 -h integrations of the trajectory equation using the OGCM's horizontal velocity fields at $15 \mathrm{~m}$ depth. The analyzed drifter positions were obtained by minimizing the linearized cost function around the background fields, viz. by reducing the distance between the observed and forecasted Lagrangian trajectory end-points (cf. Eq. A3). By variationally adding increments to the Eulerian model fields, the uncertainties related to model state variable fields (temperature, salinity, velocity and sea-level) can be expected to diminish.

\section{Design of the model experiments}

This section will describe the surface-drifter and sub-surface Argo float observations, their estimated observational errors, as well as the design of the numerical experiments wherein these data sets will be assimilated separately and in concert.

\subsection{Lagrangian observations}

The Mediterranean Surface Velocity Programme (MedSVP) has managed surface drifter operations and archived drifter data since 1986 in the Mediterranean and Black Seas (Gerin et al., 2009). The quantity of drifters operating simultaneously reached about 20 in mid-November 2005 in the Eastern Mediterranean Sea, thus providing a good opportunity for data assimilation in the fall of 2005. All drifters were SVP designs with a surface buoy and a sub-surface drogue centred at a nominal depth of $15 \mathrm{~m}$ (Gerin et al., 2009) and hence these observations are representative of the near-surface circulation. The drifter data was post-processed according to the protocol due to Hansen and Poulain (1996), i.e., the raw drifter data were edited for e.g. spikes and outliers, and thereafter interpolated at 2-hour intervals. In order to exclude high-frequency inertial and tidal signals, the data was 36hour low-pass filtered (Gerin et al., 2009), whereafter the data were resampled at a daily rate. 


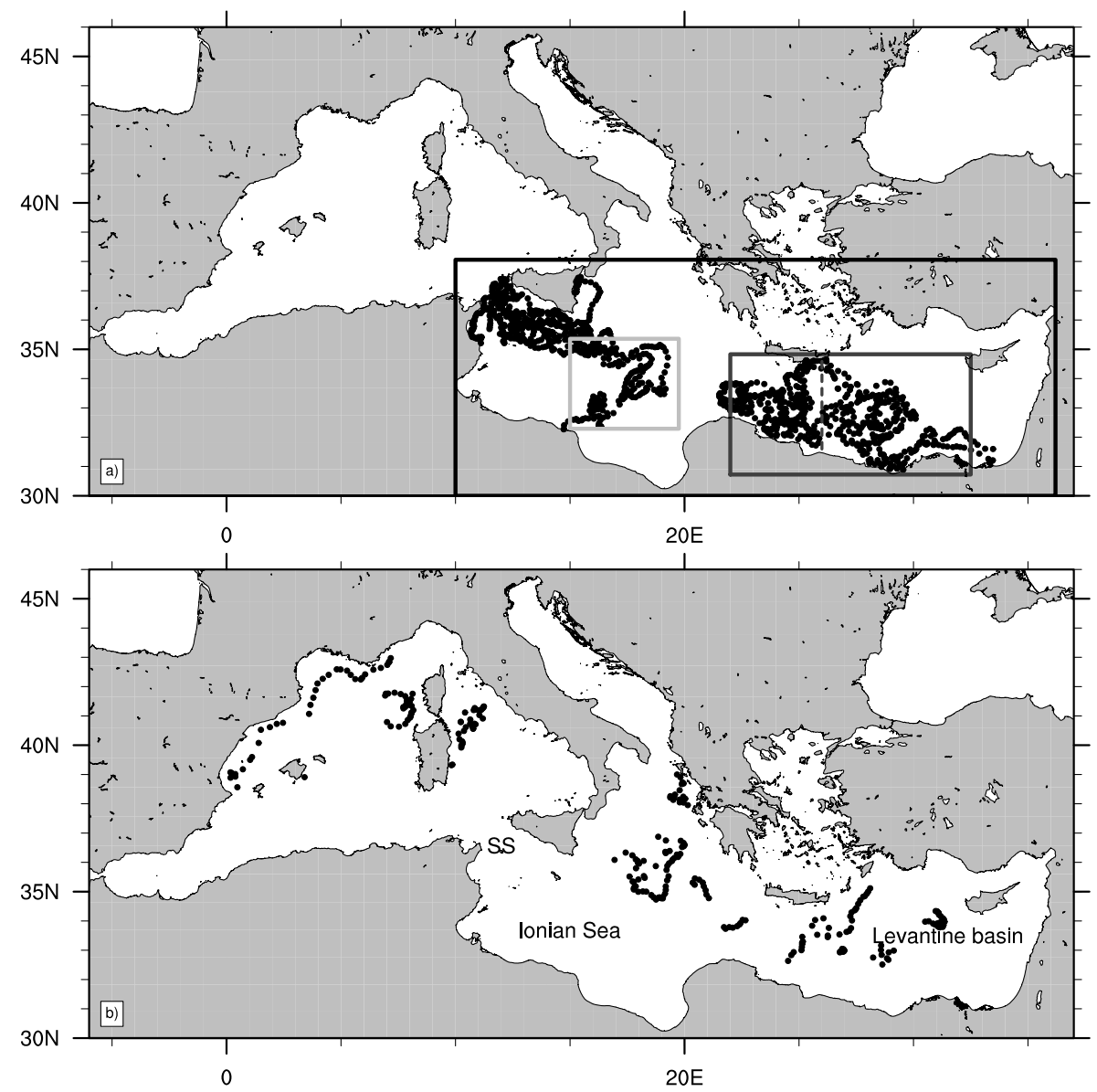

Fig. 1. Distribution of Lagrangian observations during the test period 1 September-31 December 2005: (a) Surface drifter positions, and (b) Argo float positions. The boxes indicate the location of the forthcoming zoom-ins of the Eastern Mediterranean (black), Ionian (light grey) and Levantine (dark grey) basins, respectively, while the dashed line marks the transect across the Cretan passage. Abbreviation: Strait of Sicily (SS).

Argo-float data, originating from the Coriolis Operational Oceanography data center, were post-processed and quality checked by Menna and Poulain (2010). These floats are programmed to descend to a parking depth of $350 \mathrm{~m}$ followed by a 4.5 -day drifting period, whereafter they complete the cycle by re-emerging at the sea surface to transmit data via the Argos satellite system. The position uncertainties due to instrumental errors were estimated to $1000 \mathrm{~m}$ (Gerin et al., 2009) for the drifters and 250-1500 m (Menna and Poulain, 2010) for the Argo floats.

An overview of the available surface-drifter and Argo-float positions is provided in Fig. 1. Two sub-regions with large amounts of surface drifter data can be identified from Fig. 1a: east of the Strait of Sicily and across the central part of the Ionian Sea, as well as the south-western part of the Levantine basin. The Argo-float data (cf. Fig. 1b) were sparsly scattered over the basin, present, however, in both the western and eastern parts of the Mediterranean Sea.

\subsection{Observational error sensitivity test}

In three-dimensional data assimilation it is required that each set of observations is related to an observational error comprising uncertainties related to both instrumental and representativeness errors, $\mathrm{err}_{\mathrm{tot}}=\sqrt{\mathrm{err}_{\text {instr }}^{2}+\mathrm{err}_{\mathrm{repr}}^{2}}$, to be stored in the observational-error matrix R, cf. the Appendix.

A first observational-error sensitivity test was undertaken where only the instrumental uncertainties were taken into consideration, i.e. err $_{\text {tot }}=1000 \mathrm{~m}$. This error proved to be an underestimation as OceanVar failed completely to converge towards the drifter observations. In a second test the error was increased to $\operatorname{err}_{\text {tot }}=3000 \mathrm{~m}$, and in this case OceanVar proved capable of minimizing the cost function, however, the system still suffered from convergence problems with increased CPU time as a result. A reduction was noted in the root-mean-square (RMS) misfits between the modeled and observed drifter trajectory end-points compared to a control run, indicating that drifter assimilation could improve the 
Table 1. Design of numerical experiments, the assimilated observations are marked with X. SLA (sea level anomalies), TEM (temperature profiles), SAL (salinity profiles), TRD (surface drifter positions), and TRA (Argo float positions).

\begin{tabular}{lccccc}
\hline Exp. name & SLA & TEM & SAL & TRD & TRA \\
\hline CTRL & X & X & X & & \\
SURF & X & X & X & X & \\
SURF2 & X & X & X & X & X \\
ARGO & X & X & X & & X \\
\hline
\end{tabular}

quality of the OGCM velocity field forecasts. A third and final test was done for a 5000-m observational error, which proved to yield stable OceanVar solutions with slightly reduced RMS misfits and faster computations (in terms of CPU time) compared to the results from the " 3000 -m experiment". The observational error for the Argo float positions was set to $2000 \mathrm{~m}$, as given from sensitivity tests in Nilsson et al. (2011).

The Eastern Mediterranean surface circulation is dominated by a highly variable meso-scale eddy field and the meandering Libyo-Egyptian current system, which make accurate velocity-field predictions a most challenging task. Under these circumstances the observational errors of the Lagrangian data sets are dominated by representativeness errors due to quality uncertainties of the modeled velocity fields. The dispersion in the Mediterranean Sea surface layers was studied by Pizzigalli et al. (2007) in the framework of comparing drifter observations to corresponding synthetic trajectories from a Lagrangian model (off-line integrations of the MFSPP MOM model). They investigated the seasonal dispersion variations and calculated climatological (2000-2004) dispersion estimates. According to their results, the basin-average autumn (Oct-Dec) dispersion after 1 day should be on the order of $25 \pm 15 \mathrm{~km}$. It is worth pointing out that the OGCM used in the present study is more advanced than the operational system based on MOM, however, their estimates could serve as an upper limit for the representativeness of the modeled surface fields in the Mediterranean during fall. In conclusion, the application of a $4900 \mathrm{~m}$ representativeness error (yielding a total observational error of err ${ }_{\text {tot }}=5000 \mathrm{~m}$ ) would be reasonable as it is well below the "maximum dispersion limit" for the Mediterranean Sea and furthermore smaller than the model horizontal resolution $(\sim 7 \mathrm{~km})$.

\subsection{Numerical experiment set-ups}

Four experiments were designed to evaluate the influence of Lagrangian trajectory assimilation on the model fields, subsequently referred to as CTRL, SURF, SURF2, and ARGO (cf. Table 1). All experiments were initialized with the same
Table 2. 4-month basin-average RMS misfits between model values and observations for sea-level anomalies, sea-surface temperature and salinity, as well as surface-drifter and Argo-float positions. "Near-drifter" (as defined in text) SLA RMS misfits are given within the brackets.

\begin{tabular}{lccccr}
\hline Exp. name & SLA $(\mathrm{cm})$ & $T\left({ }^{\circ} \mathrm{C}\right)$ & $S(\mathrm{psu})$ & TRD $(\mathrm{km})$ & TRA $(\mathrm{km})$ \\
\hline CTRL & $3.32(3.33)$ & 0.77 & 0.22 & 17.5 & 25.2 \\
SURF & $3.29(3.10)$ & 0.79 & 0.22 & 15.2 & 25.0 \\
SURF2 & $3.28(3.08)$ & 0.78 & 0.22 & 15.3 & 20.5 \\
ARGO & $3.31(3.36)$ & 0.77 & 0.22 & 17.7 & 21.0 \\
\hline
\end{tabular}

forcing fields on 1 September 2005, and terminated after 4 months on 31 December 2005.

The control experiment (CTRL) assimilated daily satellite SLA and SST data as well as temperature and salinity profiles, whereas the SURF experiment also included observations of surface-drifter positions. Moreover, in the SURF2 experiment surface-drifter and Argo-float positions were assimilated, and thus the surface as well as the intermediatedepth trajectories were simultaneously modified. The ARGO experiment assimilated Lagrangian data from Argo floats as well as the observations used in the CTRL experiment; the quality of the output from this model set-up has been assessed over a 3-yr period in Nilsson et al. (2011).

\section{Results and discussion}

\subsection{Statistical analysis}

The impact of Lagrangian data assimilation of surface-drifter positions on the model output was evaluated in terms of 4month basin-average RMS misfits between the observations and the forecasted temperature and salinity values, as well as the drifter and float trajectory end-points. The SLA RMS misfits were calculated both as basin averages and in close vicinity of the drifters $\left(1^{\circ}\right.$ radius and a 3-day time span), since applying only basin-mean statistics for SLA could lead to underestimating the local effects of the surface-drifter trajectory assimilation due to the large amount of satelliteobserved data in areas without surface drifters. All RMS misfits are provided in Table 2, and the "near-drifter" SLA RMS misfits are given within the brackets next to the corresponding basin-average values.

It was found that the quality of the forecasted surface temperature and salinity fields remained at the previous levels of $\sim 0.7^{\circ} \mathrm{C}$ and $\sim 0.2 \mathrm{psu}$, respectively (Tonani et al., 2009). The quality of the forecasted SLA improved by $5 \%$ in the proximity of the assimilated drifter positions, yielding a decrease of RMS differences from $3.3 \mathrm{~cm}$ in CTRL and ARGO to $3.1 \mathrm{~cm}$ in the SURF and SURF2 experiments. The basin average SLA RMS misfits remained around $3.3 \mathrm{~cm}$ for all experiments. Moreover, the accuracy of the 24-h 

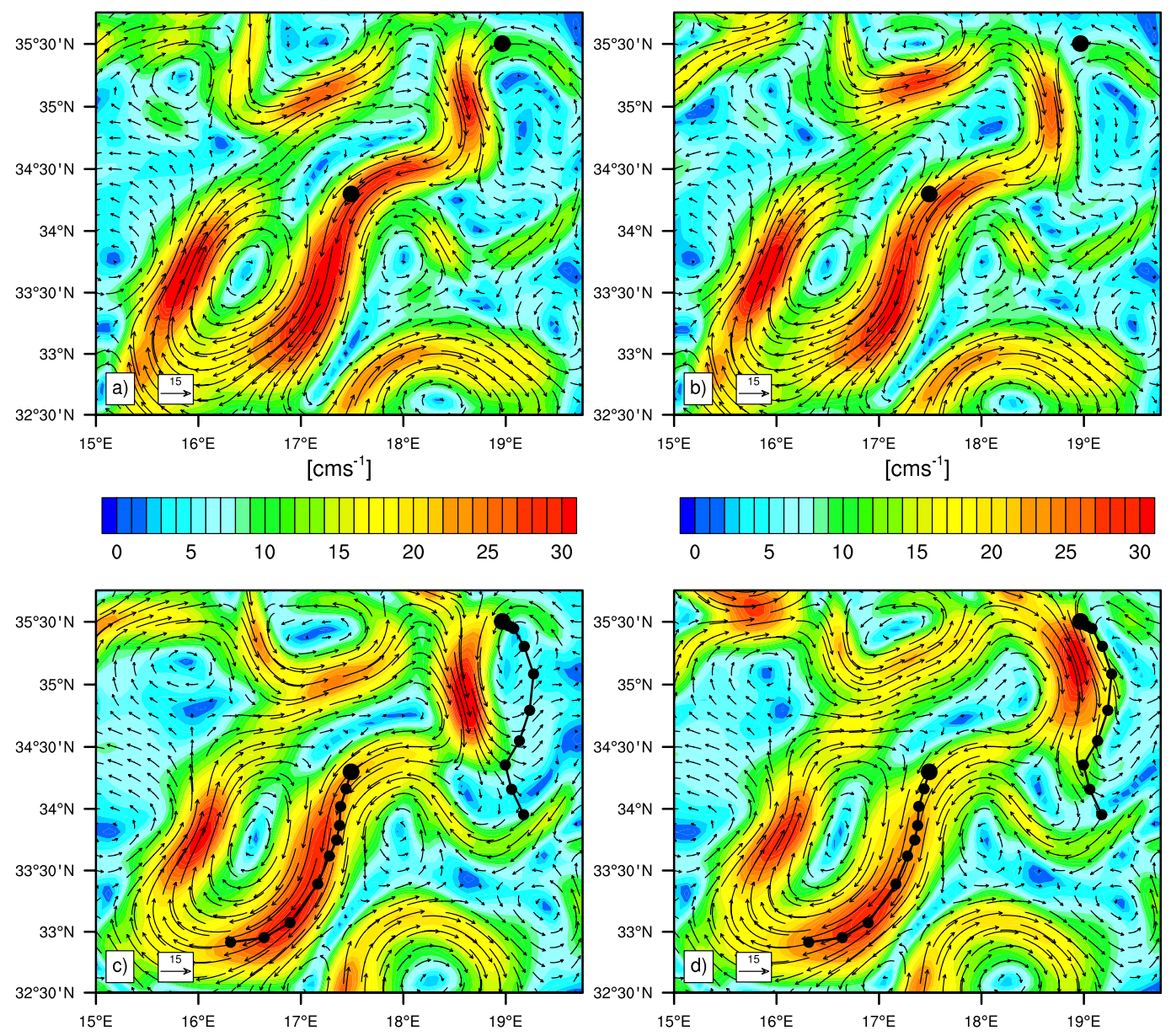

Fig. 2. Upper panels: Velocity fields at $15 \mathrm{~m}$ depth on 1 November 2005 from the (a) CTRL, and (b) SURF experiments, with the observed surface drifter positions from platforms 57319 and 59733 on 1 November indicated by large black markers. Lower panels: Velocity fields at $15 \mathrm{~m}$ depth on 10 November 2005 from the (c) CTRL, and (d) SURF experiments, with the daily observed surface drifter positions on 1-10 November shown by the black markers.

drifter-trajectory forecasts at the sea surface improved by $15 \%$ in terms of RMS distances between the observed and forecasted drifter-trajectory end-points when drifter assimilation was introduced in OceanVar, yielding an error reduction from $17.5 \mathrm{~km}$ (CTRL) to $15.2 \mathrm{~km}$ (SURF). The quality of the SURF2-forecasted SLA, temperature and salinity fields as well as the surface-drifter trajectories was maintained compared to the accuracy of the SURF fields, while the 5-day float-trajectory forecasts improved by $20 \%$, with RMS-misfit distances decreasing from $25 \mathrm{~km}$ (CTRL and SURF) to $20.5 \mathrm{~km}$ (SURF2). The RMS misfits based on the results from the ARGO experiment were in general agreement with those obtained in Nilsson et al. (2011), where it was found that the quality of the forecasted SSH, temperature and salinity fields was maintained while the sub-surface trajectory forecasts improved. The RMS misfit between the observed and forecasted float-trajectory end points was found to be around $20 \mathrm{~km}$ during the autumn of 2005 .
In conclusion, these statistical results indicate that OceanVar is capable of correcting the pressure-gradient field at different vertical levels using two different Lagrangian observational data sets without compromising (and indeed improving slightly) the quality of the other forecast variables.

\subsection{Influence of Lagrangian data assimilation on the surface fields}

Since the drifter data were from the Eastern Mediterranean basin during the 4-month test period, the comparisons of the model experiment results have been limited to this area. Next, the influence of surface-drifter-trajectory assimilation on the surface-velocity and SSH fields will be considered. Figure 2 gives an example of the evolution of the CTRL and SURF velocity fields at a depth of $15 \mathrm{~m}$ during 1-10 November 2005. In this period there were approximately four operating drifters (Gerin et al., 2009), including two units located in the Ionian Sea (57319 to the east, and 59733 to the west 

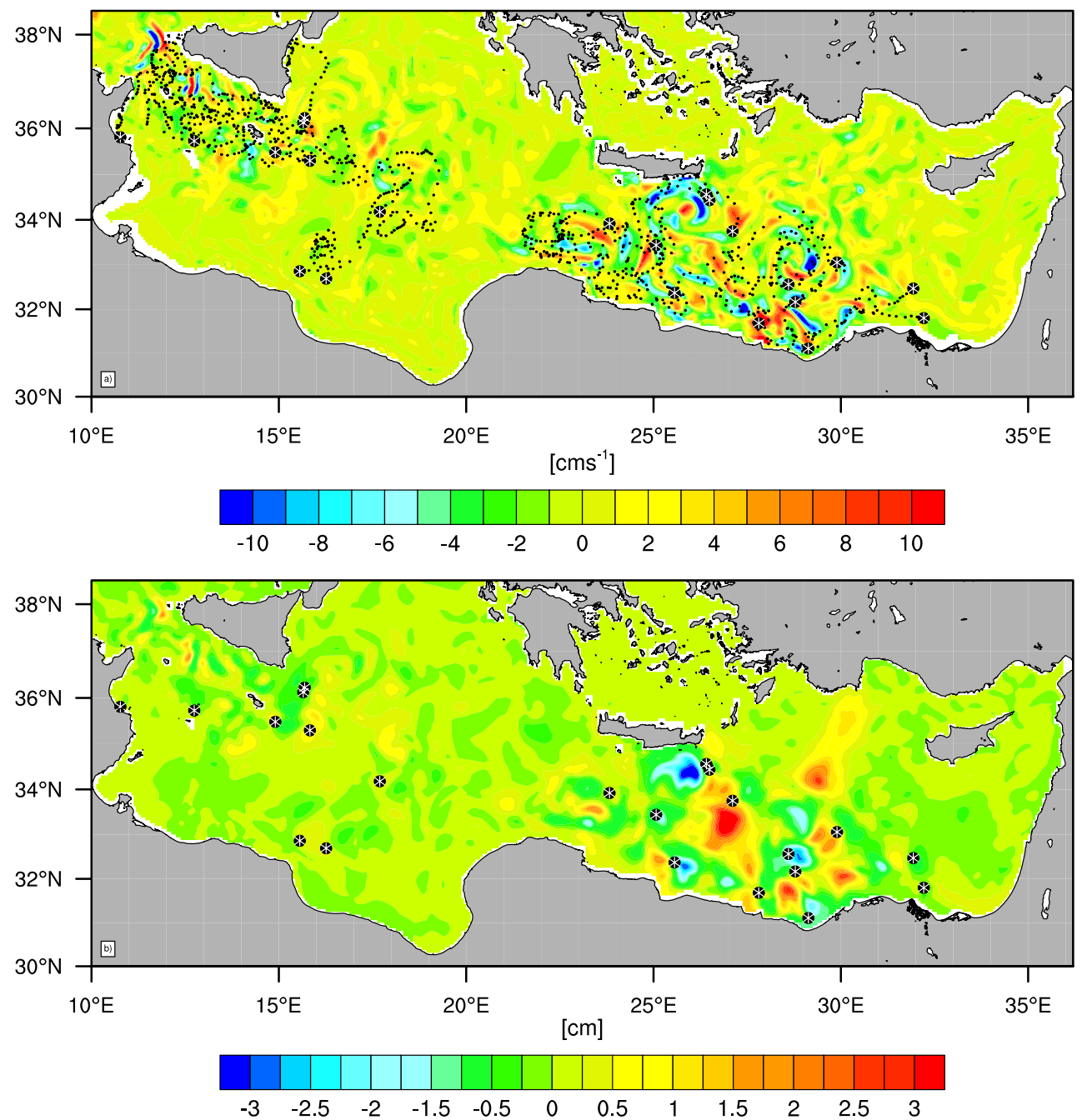

Fig. 3. Differences between the day-to-day residuals from 21 to 22 December 2005 of the CTRL and SURF (a) velocity fields at $15 \mathrm{~m}$ depth, and (b) SSH fields. Previously observed drifter positions (1 September-20 December 2005) are indicated by black dots, while the observations made on 21 December are shown by the larger black-white markers.

in the figure). The CTRL model results were compared (and validated) with these observations, and it was found that the circulation in the vicinity of drifter 59733 was well reproduced in the output on 10 November, whereas the velocity field near drifter 57319 was less accurate. An a posteriori control of the SURF experiment output showed that these velocity fields were in better agreement with the observed (and assimilated) Lagrangian trajectories, indicating that OceanVar is capable of converging the model fields towards the drifter positions in a satisfactory manner. Another example is provided from mid-December 2005 when $\sim 20$ drifters were available per day. The day-to-day differences in the model fields (21-22 December) were calculated and the subsequent differences between the CTRL and SURF residual fields are presented in Fig. 3 for the velocity fields at the 15-m depth as well as the SSH fields, along with the drifter observations from 1 September to 21 December. From this figure it is evident that most differences $\left( \pm 10 \mathrm{~cm} \mathrm{~s}^{-1}\right.$ and $\left.\pm 3 \mathrm{~cm}\right)$ are located in the immediate proximity of the drifters but not necessarily of the last assimilated positions obtained on 21 December. This suggests that previous corrections of the velocity field are still present in the "model memory", hence indicating both spatial (horizontal) and temporal propagations of the model-field corrections. Similar results were found for glider observations in Dobricic et al. (2010) and for Argofloat trajectories in Nilsson et al. (2011). Moreover, the most distinct residuals in both the velocity and SSH fields, in particular in the Cretan Passage and off the North African coast, are most likely caused by lateral shifts of the meso-scale features (gyres, eddies, coastal current meandering) due to drifter assimilation. 

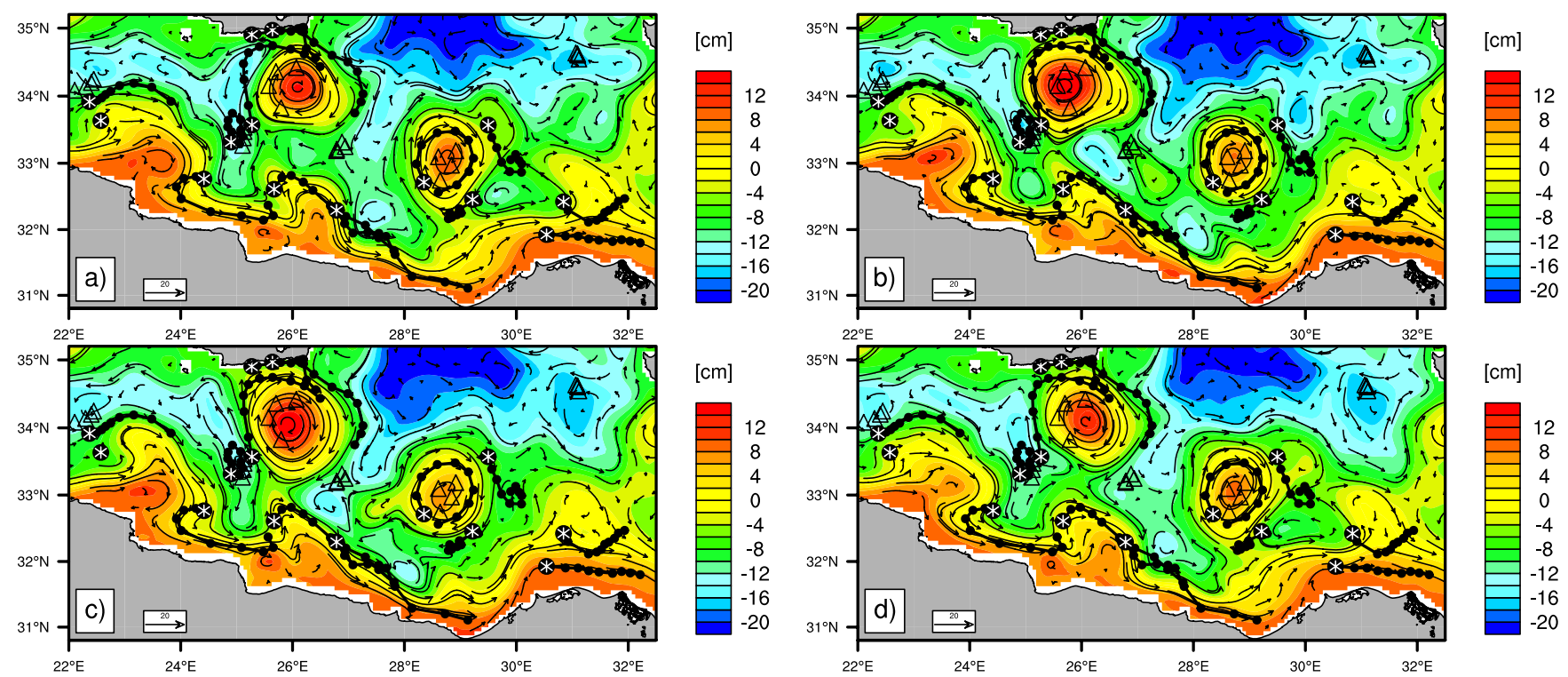

Fig. 4. Sea-surface height fields (cm) on 22 December 2005 with superimposed velocity vector fields at $15 \mathrm{~m}$ depth from the (a) CTRL, (b) SURF, (c) SURF2, and (d) ARGO experiments. The daily observed surface drifter positions during 13-22 December are indicated by the black dots with start positions in white. The Argo float positions are measured every 5 days and marked for the 1-22 December period by triangles.

The statistical analysis of the model results indicated a modest improvement of the SSH-forecast quality in the vicinity of the assimilated surface drifters. The SSH fields from all four numerical experiments on 22 December 2005 are presented in Fig. 4, with the corresponding velocityvector fields at $15 \mathrm{~m}$ depth superimposed. Here the drifter observations during 13-22 December are indicated by dots and the Argo-float positions during 1-22 December by triangles. The main features of the surface dynamics can be recognized in all cases, viz. the near-coastal currents and semipermanent anti-cyclones (Pinardi and Masetti, 2000; Gerin et al., 2009; Hamad et al., 2005). The locations of SSH minima and maxima as well as the intensity and direction of the surface currents, however, vary between the experiments, most notably in the vicinity the drifters and the floats. The modeled surface temperature and salinity fields showed corresponding shifts of the horizontal gradients compared to the SSH fields due to drifter assimilation (not shown).

It can be concluded that the drifter assimilation has an ameliorating impact on the quality of the modeled smalland meso-scale dynamics in the surface layer. In particular, assimilation changed the meandering patterns of the LibyoEgyptian (LE) current along the African coast near 26$28^{\circ} \mathrm{E}$, and shifted slightly the location and shape of the IeraPetra (IP, $\sim 26^{\circ} \mathrm{E}, 34^{\circ} \mathrm{N}$ ) and Mersa-Matruh $\left(\mathrm{MM}, \sim 29^{\circ} \mathrm{E}\right.$, $33^{\circ} \mathrm{N}$ ) in the SURF and SURF2 velocity fields. It was established from the drifter-position RMS misfits that the SURF and SURF2 surface velocity and SSH output was more accurate than the CTRL results, and furthermore, that the quality of the SURF2 SSH fields was slightly improved compared to the SURF results. Thus the SSH fields from the drifter assimilation experiments were found to be more realistic than the CTRL fields, since the modeled sea-level gradients are in better agreement with the observed drifter trajectories (as to be expected in areas characterized by geostrophic flow).

It should be noted that the SSH and surface velocity fields in Fig. 4 from the CTRL and ARGO experiments bear a large resemblances in the near-drifter areas (same "flaws"), while similarities were found in the SURF2 and ARGO flow structures near the observed and assimilated Argo floats (similar corrections of surface fields due to intermediate-depth trajectory assimilation). This example indicates how subtly the velocity field corrections have been blended into the model fields from the Lagrangian data assimilation experiments, to be compared with the less accurate CTRL output. Furthermore, these findings confirm that assimilation of subsurface trajectories can influence and occasionally improve the strength and direction of the modeled surface flow, as suggested in Nilsson et al. (2011).

\subsection{Impact on the intermediate velocity fields due to trajectory corrections}

The influence of Lagrangian data assimilation on meso-scale dynamics was studied in the upper $800 \mathrm{~m}$ of the water column in the Levantine basin. The RMS misfits between the observed and forecasted drifter positions indicated that surfacedrifter assimilation could also improve the forecasting capabilities of the Argo trajectories at $350 \mathrm{~m}$ depth, viz. $20.5 \mathrm{~km}$ (SURF2) and $21 \mathrm{~km}$ (ARGO) in Table 2. However, the 

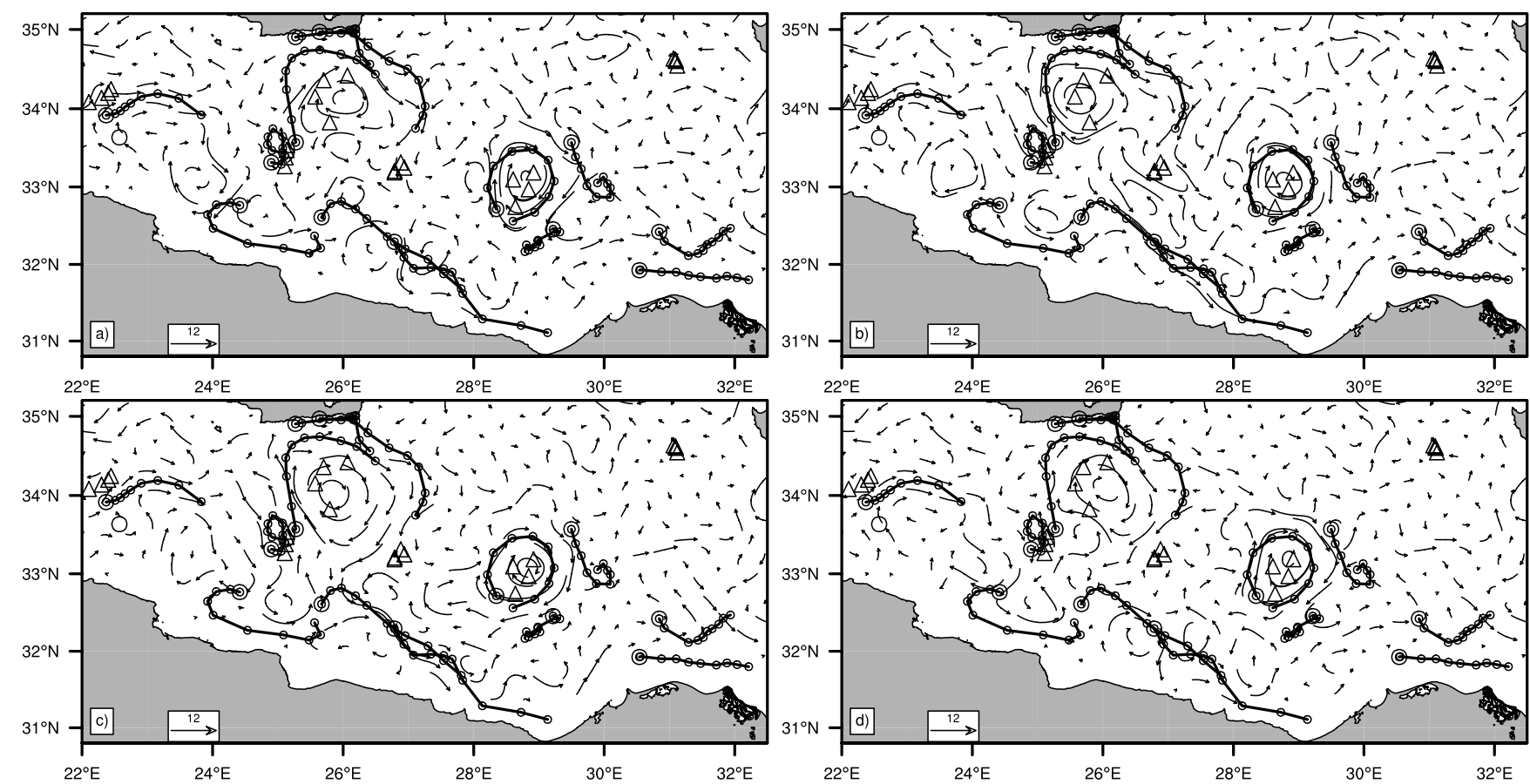

Fig. 5. Velocity vector fields at 365-m depth on 22 December 2005 from the (a) CTRL, (b) SURF, (c) SURF2, and (d) ARGO experiments. The daily observed surface drifter positions during 13-22 December are indicated by the black dots with double-circled start positions. The Argo float positions are measured every 5 days and marked for the 1-22 December period by triangles.

difference between these estimates $(500 \mathrm{~m})$ is smaller than the associated observational errors $(2000 \mathrm{~m}$ for floats, and $5000 \mathrm{~m}$ for drifters), and thus the increased float trajectory accuracy in the SURF2 experiment should not be overemphasized.

A comparison of the model velocity fields at $365 \mathrm{~m}$ depth on 22 December 2005 is shown in Fig. 5, with superimposed drifter and Argo trajectory data. Similar differences in flow patterns compared to those observed in Fig. 4 can be identified for each experiment, such as the changes in the small-scale dynamics along the LE current as well as the altered locations and dimensions of the IP and MM gyres. Furthermore, the model results presented in this figure show that surface-drifter assimilation is capable of influencing, and possibly correcting, the Levantine circulation down to at least Argo-float parking depth. Moreover, the float-trajectory corrections yielded improvements in the intermediate-depth velocity fields, and in particular near $31^{\circ} \mathrm{E}, 35^{\circ} \mathrm{N}$, where the data assimilation appears to have had a decelerating effect on the near-float velocity field.

Finally, a vertical transect of the zonal velocities across the Cretan passage $\left(26^{\circ} \mathrm{E}\right)$ on 22 December 2005 was chosen in order to illustrate the differences at depth between the model fields, cf. Fig. 6. This transect, on this day, was opportune for detailed analysis as 3 drifters (nr 59753 at $26^{\circ} 12^{\prime} \mathrm{E}$, $34^{\circ} 37^{\prime} \mathrm{N}$; nr 59757 at $26^{\circ} 15^{\prime} \mathrm{E}, 34^{\circ} 42^{\prime} \mathrm{N}$; and, nr 59755 at $25^{\circ} 39^{\prime} \mathrm{E}, 32^{\circ} 12^{\prime} \mathrm{N}$ ) and one float (nr 50755 at $26^{\circ} 4^{\prime} \mathrm{E}$, $34^{\circ} 25^{\prime} \mathrm{N}$ ) were located near the $26^{\circ}$ E-meridional, which provided favorable circumstances for evaluating effects of combined surface and intermediate-depth Lagrangian data assimilation.

The strong east- and westward velocities of the Atlantic waters in the upper $200 \mathrm{~m}$ of the transect (Hamad et al., 2006) are caused by the LE current and the IP gyre, showing typical velocities of $10-30 \mathrm{~cm} \mathrm{~s}^{-1}$ (Gerin et al., 2009). The strength of the surface velocities varies between the four experiments on the order of $\pm 5-10 \mathrm{~cm} \mathrm{~s}^{-1}$ (cf. Fig. 3a), and these differences are most likely related to the laterally shifted baroclinic-instability front of the meandering coastal current (cf. Fig. 4). The IP gyre seems to be clearly influenced by the Lagrangian assimilation of drifter and Argo data, both in terms of current velocities and the vertical extent of the gyre. However, some of the velocity variability could be explained by the fact that the gyre is centered differently in each model field, although, Figs. 4 and 5 also revealed changes in the velocity-field intensity from the different numerical experiments. All model setups including trajectory assimilation (SURF2, ARGO, and to some extent SURF) appear to have a limiting effect on the gyre depth. In the CTRL velocity output, the intense core of the IP gyre extends down to $\sim 600-700 \mathrm{~m}$, while in SURF2 and ARGO this depth has been reduced by approximately $100 \mathrm{~m}$. This modified gyre depth would be in general agreement with the results due to Popov (2004), who estimated observationally the vertical scales of the IP gyre to approximately $500 \mathrm{~m}$. Moreover, the results from the SURF2 and ARGO experiments imply that 

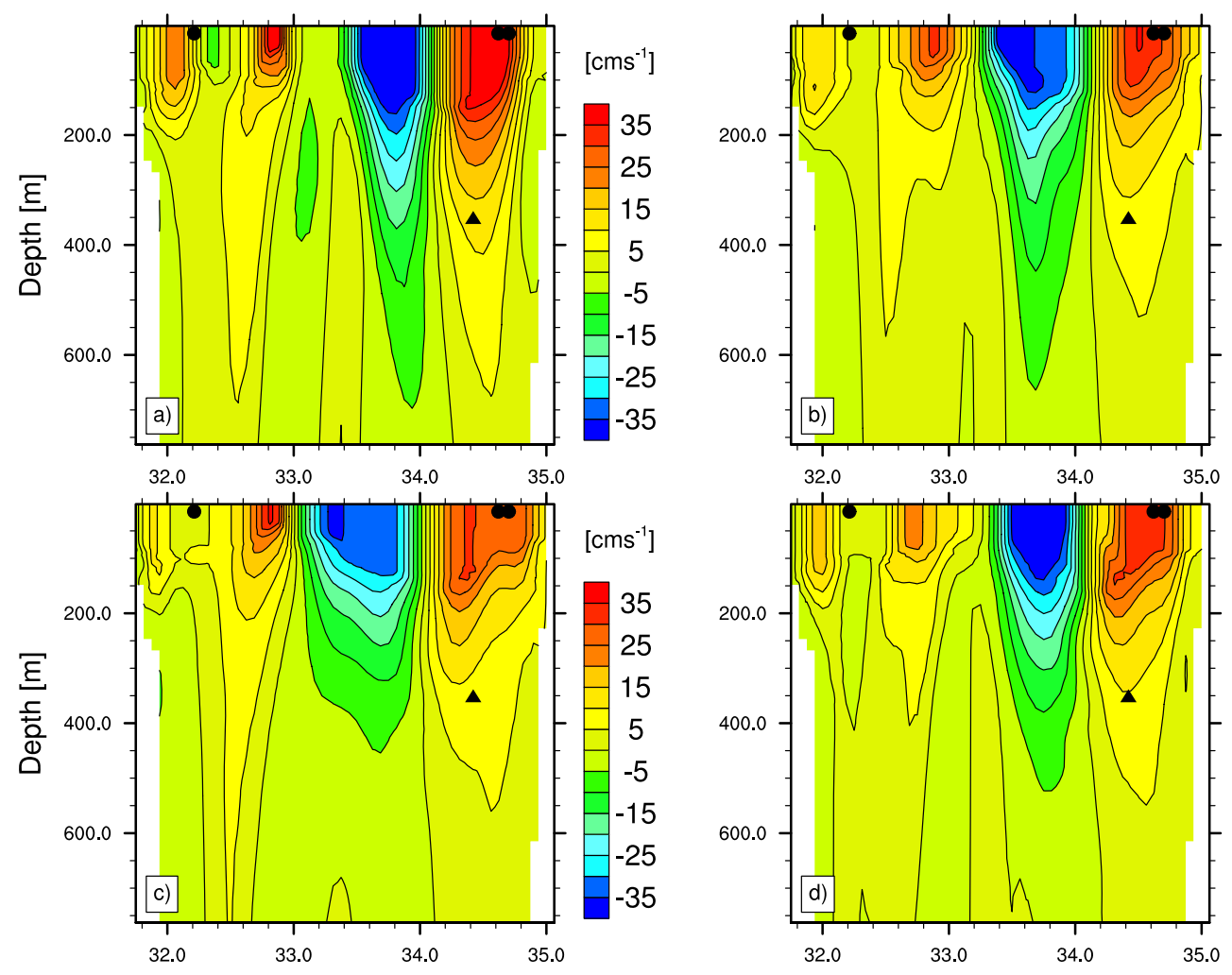

Fig. 6. Zonal velocity transect across the Cretan Passage (26 E) on 22 December 2005: (a) CTRL, (b) SURF, (c) SURF2, and (d) ARGO. The surface drifter (Argo float) positions on 21 December are indicated by the black dots (triangle).

assimilation of float trajectories tends to reduce the velocities of the intermediate-layer waters.

\section{Conclusions}

Four numerical experiments have been presented where variational assimilation was undertaken of Lagrangian observations from surface drifters and Argo floats (together and separately) during a 4-month period, thus changing the Eulerian $\mathrm{SSH}$, temperature, salinity and velocity fields in a Mediterranean OGCM. The results of these investigations indicated that the quality of the surface and intermediate-depth velocity fields improves when the Lagrangian data sets are assimilated, yielding more accurate surface-drifter and Argofloat trajectory forecasts ( $\sim 15$ and $\sim 20 \%$, respectively) in terms of relative differences in RMS misfits. Moreover, the $\mathrm{SSH}$ gradient fields from the drifter-assimilation experiment proved to be in better agreement with observations (the SSH forecast improved locally by $\sim 5 \%$ ) compared to the output from the control experiment. The basin-mean RMS misfits of temperature and salinity remained unchanged, while the local impact close to the drifters could not be evaluated due to the sparsity of observations.
Local studies of the model fields from the four experiments gave an interesting insight on the influence of Lagrangian trajectory corrections on the surface and intermediate velocity fields. It was shown that the best quality of the model forecasts was obtained when all observational data sets were assimilated simultaneously by OceanVar. Improving the accuracy of the modeled surface meso-scale dynamics is of particular interest for improving oil-spill predictions and the capability of back-tracking objects at sea, both of which are determined off-line using stored OGCM velocity fields.

In the present study, the influence of inertial currents on the model analyses have not been taken into account, since these frequencies are outside of the time range dealt with here. However, it would be important to examine these effects in detail within the framework of drifter-trajectory assimilation in a future study.

\section{Appendix A}

\section{The Ocean Var assimilation scheme and trajectory model}

This Appendix will provide a general overview of the OceanVar assimilation scheme and its built-in trajectory model, however, detailed descriptions are available in Dobricic and Pinardi (2008); Nilsson et al. (2011). 
The OceanVar cost function is linearized around the background state vector $\mathbf{x}_{b}$, which contains a first guess of the model state (in this case the 1-day forecasts); the linearization yields a quadratic function:

$J=\frac{1}{2} \delta \mathbf{x}^{T} \mathbf{B}^{-1} \delta \mathbf{x}+\frac{1}{2}(\mathbf{H}(\delta \mathbf{x})-\mathbf{d})^{T} \mathbf{R}^{-1}(\mathbf{H}(\delta \mathbf{x})-\mathbf{d})$,

where $\delta \mathbf{x}=\mathbf{x}-\mathbf{x}_{b}$ are the increments given by the minimized differences between the model state vector (which contain the temperature, salinity, velocity and sea-level model output in matrix form as $\mathbf{x}=[T S U V \eta]^{T}$ ) and the background state vector. The so-called misfits (the differences between the observations, contained in $\mathbf{y}$, and the background values) are given by $\mathbf{d}=\left[\mathbf{y}-H\left(\mathbf{x}_{\mathbf{b}}\right)\right]$, where the non-linear operational operator, $H$, transfers the model variables onto the observational grid, hereby allowing direct comparisons between the two data sets. B represents the background error covariance matrix, $\mathbf{R}$ the observational-error covariance matrix, and $\mathbf{H}$ is the linearized observational operator, and ${ }^{T}$ denotes the vector transpose (e.g. Lorenc, 1997).

The increments $\delta \mathbf{x}$ are stored as a matrix $(\mathbf{V})$ in control vector space, where $\mathbf{B}=\mathbf{V} \mathbf{V}^{T}$ is satisfied thus assuring the inversion of the problem. $\mathbf{B}$ is, moreover, constructed as a sequence of linear operators $\mathbf{V}=\mathbf{V}_{D} \mathbf{V}_{u v} \mathbf{V}_{\eta} \mathbf{V}_{H} \mathbf{V}_{V}$, which facilitates the propagation of the corrections in the full three-dimensional model fields through the application of vertical EOFs, horizontal Gaussian covariance functions, a barotropic model, geostrophic-balance assumptions, and a coastal damping filter (cf. Dobricic and Pinardi, 2008).

Nilsson et al. (2011) presented the implementation of a trajectory model in the OceanVar non-linear observational operator $H$, with the ultimate aim to improve the MFS intermediate-depth velocity forecasts by assimilation of observed Argo-float positions. Here, this trajectory model has been modified to also produce daily drifter-trajectory forecasts by performing 24-hour integrations of the particle advection equation, $d \mathbf{r} / d t=\mathbf{u}_{\mathbf{L}}(\mathbf{r}(t), t)$; $\mathbf{r}$ being the drifter position, and $\mathbf{u}_{\mathbf{L}}$ the Lagrangian velocities in the horizontal plane at the drifter-drogue depth $(15 \mathrm{~m})$.

In an Eulerian frame of reference and for one time step, the discretized time-integrated advection equation (implemented in the OceanVar non-linear observational operator $H$ ) can be represented as follows:

$\mathbf{r}\left(t_{f}\right)=\mathbf{r}\left(t_{i}\right)+\int_{t_{i}}^{t_{f}} \mathcal{L}(\mathbf{r}(t)) \mathbf{u}(t) d t$

where $t_{i}$ and $t_{f}=t_{i}+\Delta t$ indicates the limits of time interval (here, $\Delta t=1$ day), and the Lagrangian velocities $\mathbf{u}_{\mathbf{L}}$ are expressed in terms of the Eulerian velocities $\mathbf{u}$ as $\mathbf{u}_{\mathbf{L}}(\mathbf{r}(t), t)=\mathcal{L}(\mathbf{r}(t)) \mathbf{u}(t), \mathcal{L}$ being the bilinear Lagrange interpolator.

Equation A2 was subsequently subjected to a tangentlinear approximation (Taillandier et al., 2006b) so that Eulerian velocity increments $\delta \mathbf{u}$ could be retrieved and used as input in the linearized observational operator $\mathbf{H}$.

$\delta \mathbf{r}\left(t_{f}\right)=\delta \mathbf{r}\left(t_{i}\right)+\int_{t_{i}}^{t_{f}}\left(\left.\frac{\partial \mathbf{u}_{\mathbf{L}}}{\partial \mathbf{u}}\right|_{r=r_{b}} \delta \mathbf{u}+\left.\frac{\partial \mathbf{u}_{\mathbf{L}}}{\partial \mathbf{r}}\right|_{u=u_{b}} \delta \mathbf{r}\right) d t$.

where the position and the Eulerian velocity increments $\left(\delta \mathbf{r}=\mathbf{r}-\mathbf{r}_{\mathbf{b}}\right.$ and $\left.\delta \mathbf{u}=\mathbf{u}-\mathbf{u}_{\mathbf{b}}\right)$ are evaluated around the background velocity $u_{b}$ and background position $r_{b}$. The equality of Eq. A3 is assumed to be fulfilled when the higherorder terms in Eq. A2 are sufficiently small. A thorough description of the position- and velocity-increment computations and the Lagrangian data assimilation is given in Nilsson et al. (2011) Sect. 2.4, however this Appendix serves as a reminder that the non-linear trajectory model (Eq. A2) computes the drifter forecasts, while the minimum values of $\delta \mathbf{r}$ and $\delta \mathbf{u}$ are obtained by iterations of Eq. A3 thus yielding the Ocean Var drifter-position "analysis" values. In the OceanVar daily routine, the initial drifter (and float) positions are given by the corresponding observed coordinates, $\mathbf{r}\left(t_{i}\right)=\mathbf{r}^{\mathrm{obs}}\left(t_{i}\right)$, i.e. Eq. A3 is only perturbed around the final positions, hence $\delta \mathbf{r}\left(t_{i}\right)=0$.

Acknowledgements. This work was part of the activities in the INGV study program "Programma Internazionale di Studi Avanzati sull'Ambiente e sul Clima", funded by the "Fondazione Cassa di Risparmio di Bologna", and it was supported by the European Commission MyOcean Project (SPA.2007.1.1.01, development of upgrade capabilities for existing GMES fast-track services and related operational services, grant agreement 218812-1-FP7-SPACE 2007-1).

Post-processed drifter and float data sets were obtained from the MedSVP (http://nettuno.ogs.trieste.it/sire/medsvp), and the MedArgo Centre (http://nettuno.ogs.trieste.it/sire/medargo), OGS, Italy. P.M.P. was partially supported by the US Office of Naval Research under grants N000140510281 and N000140610391. J.A.U.N. acknowledges the support of Galostiftelsen Stockholm and the Foundation Blanceflor Ludoviso-Boncompagni, nee Bildt. Thanks are due to the Nordic Institute for Theoretical Physics (Nordita) for their program on Predictability. Valuable comments by two unknown reviewers on a previous version of the manuscript are also gratefully acknowledged. The English proofreading of the material by P. Lundberg is much appreciated.

Edited by: E. J. M. Delhez

\section{References}

Coppini, G., De Dominicis, M., Zodiatis, G., Lardner, R., Pinardi, N., Santoleri, R., Colella, S., Bignami, F., Hayes, D. R., Soloviev, D., Georgiou, G., and Kallos, G.: Hindcast of oilspill pollution during the Lebanon crisis in the Eastern Mediterranean, July-August 2006, Mar. Pollut. Bul., 62, 140-153, doi:10.1016/j.marpolbul.2010.08.021, 2011.

Dobricic, S. and Pinardi, N.: An oceanographic three-dimensional variational data assimilation scheme, Ocean Modell., 22, 89$105,2008$. 
Dobricic, S., Pinardi, N., Adani, M., Bonazzi, A., Fratianni, C., and Tonani, M.: Mediterranean Forecasting System: an improved assimilation scheme for sea-level anomaly and its validation, Q. J. R. Meteorol. Soc., 131, 3627-3642, 2005.

Dobricic, S., Pinardi, N., Testor, P., and Send, U.: Impact of data assimilation of glider observations in the Ionian Sea (Eastern Mediterranean), Dyn. Atm. Ocean., 50, 78-92, 2010.

Fan, S., Oey, L.-Y., and Hamilton, P.: Assimilation of drifter and satellite data in a model of the Northeastern Gulf of Mexico, Cont. Shelf. Res., 24, 1001-1013, 2004.

Gerin, R., Poulain, P.-M., Taupier-Letage, I., Millot, C., Ben Ismail, S., and Sammari, C.: Surface circulation in the Eastern Mediterranean using drifters (2005-2007), Ocean Sci., 5, 559574, doi:10.5194/os-5-559-2009, 2009.

Hansen, D. V. and Poulain, P.-M.: Quality control and interpolations of WOCE-TOGA drifter data, J. Atm. Ocean. Technol., 13, 900909, 1996.

Hamad, N., Millot, C., and Taupier-Letage, I.: A new hypothesis about the surface circulation in the eastern basin of the Mediterranean Sea, Prog. Oceanogr., 66, 287-298, 2005.

Hamad, N., Millot, C., and Taupier-Letage, I.: The surface circulation in the eastern basin of the Mediterranean Sea, Sci. Mar., 70, 457-503, 2006.

Le Traon, P. Y., Nadal, F., and Ducet, N.: An improved mapping method of multisatellite altimeter data, J. Atm. Ocean. Technol., 15, 522-533, 2003.

Lorenc, A. C.: Development of an operational variational assimilation scheme, J. Meteorol. Soc. Japan, 75, 339-346, 1997.

Madec, G., Delecluse, P., Imbard, M., and Levy, C.: OPA8.1 Ocean General Circulation Model reference manual, Note du Pole de modelisazion, Institut Pierre-Simon Laplace (IPSL), France, 11, 1998.

Manzella, G. M. R., Reseghetti, F., Coppini, G., Borghini, M., Cruzado, A., Galli, C., Gertman, I., Gervais, T., Hayes, D., Millot, C., Murashkovsky, A., Özsoy, E., Tziavos, C., Velasquez, Z., and Zodiatis, G.: The improvements of the ships of opportunity program in MFS-TEP, Ocean Sci., 3, 245-258, doi:10.5194/os3-245-2007, 2007.

Marullo, S., Buongiorno Nardelli, B., Guarracino, M., and Santoleri, R.: Observing the Mediterranean Sea from space: 21 years of Pathfinder-AVHRR sea surface temperatures (1985 to 2005): re-analysis and validation, Ocean Sci., 3, 299-310, doi:10.5194/os-3-299-2007, 2007.

Menna, M. and Poulain, P. M.: Mediterranean intermediate circulation estimated from Argo data in 2003-2010, Ocean Sci., 6, 331-343, doi:10.5194/os-6-331-2010, 2010.

Molcard, A., Piterbarg, L. I., Griffa, A. M. O. T., and Mariano, A. J.: Assimilation of drifter observations for the reconstruction of the Eularian circulation field, J. Geophys. Res., 108, C3, 3056, doi:10.1029/2001JC001240, 2003.

Nilsson, J. A. U., Dobricic, S., Pinardi, N., Taillandier, V., and Poulain, P.-M.: On the assessment of Argo float trajectory assimilation in the Mediterranean Forecasting System, Ocean. Dynam., 61, 1475-1490, doi:10.1007/s10236-011-0437-0, 2011.
Ozgokmen, T. M., Molcard, A., Chin, T. M., Piterbarg, L. I., and Griffa, A.: Assimilation of drifter observations in primitive equation models of midlatitude ocean circulation, J. Geophys. Res., 108, C7, 3238, doi:10.1029/2002JC001719, 2003.

Picco, P., Cappalletti, A., Sparnocchia, S., Schiano, M. E., Pensieri, S., and Bozzano, R.: Upper layer current variability in the Central Ligurian Sea, Ocean Sci., 6, 825-836, doi:10.5194/os-6825-2010, 2010.

Pinardi, N. and Coppini, G.: Preface "Operational oceanography in the Mediterranean Sea: the second stage of development", Ocean Sci., 6, 263-267, doi:10.5194/os-6-263-2010, 2010.

Pinardi, N. and Masetti, E.: Variability of the large scale general circulation of the Mediterranean Sea from observations and modelling: a review, Palaeogeogr. Palaeoclimatol. Palaeoecol., 158, 153-173, 2000.

Pinardi, N., Allen, I., Demirov, E., De Mey, P., Korres, G., Lascaratos, A., Le Traon, P.-Y., Maillard, C., Manzella, G., and Tziavos, C.: The Mediterranean ocean forecasting system: first phase of implementation (1998-2001), Ann. Geophys., 21, 3-20, doi:10.5194/angeo-21-3-2003, 2003.

Pizzigalli, C., Rupolo, V., Lombardi, E., and Blanke, B.: Seasonal probability dispersion maps in the Mediterranean Sea obtained from the Mediterranean Forecasting System Eulerian velocity fields, J. Geophys. Res., 112, doi:10.1029/2006JC003870, 2007.

Popov, Y.: Genesis and structure of the anticyclonic Ierapetra zone in the Levantine basin, Phys. Oceanogr., 14, 234-242, 2004.

Poulain, P.-M., Barbanti, R., Font, J., Cruzado, A., Millot, C., Gertman, I., Griffa, A., Molcard, A., Rupolo, V., Le Bras, S., and Petit de la Villeon, L.: MedArgo: a drifting profiler program in the Mediterranean Sea, Ocean Sci., 3, 379-395, doi:10.5194/os3-379-2007, 2007.

Taillandier, V., Griffa, A., and Molcard, A.: A variational approach for the reconstruction of regional scale Eulerian velocity fields from Lagrangian data, Ocean Modeling, 13, 1-24, $2006 \mathrm{a}$.

Taillandier, V., Griffa, A., Poulain, P.-M., and Béranger, K.: Assimilation of ARGO float positions in the North Western Mediterranean Sea and impact on ocean circulation simulations, Geophys. Res. Lett., 33, L11604, doi:10.1029/2005GL025552, 2006 b.

Tonani, M., Pinardi, N., Dobricic, S., Pujol, I., and Fratianni, C.: A high-resolution free-surface model of the Mediterranean Sea, Ocean Sci., 4, 1-14, doi:10.5194/os-4-1-2008, 2008.

Tonani, M., Pinardi, N., Fratianni, C., Pistoia, J., Dobricic, S., Pensieri, S., de Alfonso, M., and Nittis, K.: Mediterranean Forecasting System: forecast and analysis assessment through skill scores, Ocean Sci., 5, 649-660, doi:10.5194/os-5-649-2009, 2009. 